\title{
Supporting Information \\ Structural distortion induced by manganese activation in lithium-rich layered cathode
}

\author{
Liguang Wang ${ }^{1,4}$, Alvin Dai ${ }^{2}$, Wenqian $\mathrm{Xu}^{3}$, Sungsik Lee ${ }^{3}$, Wonsuk Cha ${ }^{3}$, Ross Harder ${ }^{3}$, Tongchao Liu, ${ }^{2}$ Yang \\ Ren $^{3}$, Geping Yin ${ }^{1}$, Pengjian Zuo ${ }^{1 *}$, Jun Wang ${ }^{4 *}$, Jun Lu², Jiajun Wang ${ }^{1 *}$ \\ ${ }^{1}$ School of Chemistry and Chemical Engineering, Harbin Institute of Technology, Harbin 150001, China \\ ${ }^{2}$ Chemical Sciences and Engineering Division, Argonne National Laboratory, 9700 South Cass Avenue, \\ Lemont, IL 60439, USA \\ ${ }^{3}$ X-ray Science Division, Argonne National Laboratory, 9700 South Cass Avenue, Argonne, IL 60439, USA \\ ${ }^{4}$ National Synchrotron Light Source II, Brookhaven National Laboratory, Building 743 Ring Road, Upton, NY \\ 11973, USA
}




\section{Materials and Methods}

Material preparation. LR-NCM material was synthesized with $\mathrm{Mn}_{0.666} \mathrm{Ni}_{0.167} \mathrm{Co}_{0.167} \mathrm{CO}_{3}$ precursor and $\mathrm{LiOH} \cdot \mathrm{H}_{2} \mathrm{O}$ using a solid-state reaction. ${ }^{1} \mathrm{Mn}_{0.666} \mathrm{Ni}_{0.167} \mathrm{Co}_{0.167} \mathrm{CO}_{3}$ precursor was prepared with a traditional co-precipitation method, where $\mathrm{MnSO}_{4} \cdot \mathrm{H}_{2} \mathrm{O}, \mathrm{NiSO}_{4} \cdot \mathrm{H}_{2} \mathrm{O}$, and $\mathrm{CoSO}_{4} \cdot \mathrm{H}_{2} \mathrm{O}$ material, at a molar ratio of $4: 1: 1$, were dissolved in deionized water to obtain a 2.0 M TM solution. This solution was then slowly pumped into a $2 \mathrm{~L}$ tank and continuously stirred under nitrogen atmosphere. The solution $\mathrm{pH}$ value was maintained at 7.5 by the $\mathrm{Na}_{2} \mathrm{CO}_{3}$ and $\mathrm{NH}_{3} \cdot \mathrm{H}_{2} \mathrm{O}$ solutions, and reacted for $12 \mathrm{~h}$ to obtain $\mathrm{Mn}_{0.666} \mathrm{Ni}_{0.167} \mathrm{Co}_{0.167} \mathrm{CO}_{3}$ precursor. Precursor was then mixed with $\mathrm{LiOH} \cdot \mathrm{H}_{2} \mathrm{O}(1 \mathrm{~mol} \%$ excess $)$ and calcined at $900^{\circ} \mathrm{C}$, for $20 \mathrm{~h}$ in atmospheric conditions, to achieve the LR-NCM material.

Physical characterization. 3D nano-tomography was performed on the pristine LR-NCM material at beamline 8-BM-B, Advanced Photon Source (APS), Argonne National Laboratory (ANL), which is a transitional program from the National Synchrotron Light Source II (NSLS II). Nano-tomography was collected at below Ni K-edge (8359 eV) and above Mn K-edge $(7689 \mathrm{eV})$, respectively, to resolve elemental distribution. 1081 projections were collected at angles of $-90^{\circ}$ to $90^{\circ}$ and a field view of $40 \times 40 \mu \mathrm{m}^{2}$ for use in further $3 \mathrm{D}$ reconstruction. ${ }^{2}$ Synchrotron X-ray diffraction patterns of pristine LR-NCM and pair distribution function experiments on $\mathrm{Li}_{2} \mathrm{MnO}_{3}$ samples were collected at beamline 11-ID-C, APS, ANL, with an Xray wavelength of $0.1173 \AA$. Average crystal structures were characterized with Rietveld refinement of the XRD data using GSAS-II and FullProf packages. The two-phase model was used in refinements. The Chebyschev function was used to fit the background noise and the Pseudo-Voigt function was used for peak profiling.

Electrochemical tests. Electrochemical properties of LR-NCM were tested in CR2032-type coin cells using a multichannel potentiostat (Biologic VMP3) controlled by EC-lab software. Electrodes consisted of $80 \mathrm{wt} \%$ LR-NCM, $10 \mathrm{wt} \%$ carbon black, and $10 \mathrm{wt} \%$ PVDF binder. Coin cells were assembled in an argon-filled glovebox, with moisture and oxygen levels of less than $0.5 \mathrm{ppm}$, using $1 \mathrm{M} \mathrm{LiPF}_{6}$, a mixed ethylene carbonate and diethyl carbonate $(1: 1)$ electrolyte, and $2 \%$ fluoroethylene carbonate as the additive. All batteries in this study were tested at room temperature. 
In operando XRD. In operando PXRD experiments were performed on CR2032-type coin cells with $3 \mathrm{~mm}$ diameter Kapton windows at beamline 17-BM-B, APS, ANL. The synchrotron X-ray wavelength was $0.4526 \AA$. Electrode pellets consisted of $60 \mathrm{wt} \%$ LR-NCM, $20 \mathrm{wt} \%$ carbon black, and $20 \mathrm{wt} \%$ PTFE binder. Diffraction patterns were collected at each charge state with a $10 \mathrm{~s}$ exposure time for each pattern. 10 minutes were allotted between scans as rest time to avoid long term X-ray exposure, which could negatively impact samples. Each operando PXRD pattern was fitted with a layered-rhombohedral structure $(R \overline{3} \mathrm{~m}$ space group) using the GSAS-II package to obtain lattice parameters at various charge states. In situ TR-XRD experiments were performed by heating cells from $30^{\circ} \mathrm{C}$ to $650^{\circ} \mathrm{C}$ under Ar gas flow with a similar set-up to prior experiments. ${ }^{3}$ The samples used for TR-XRD experiments were LRNCM materials charged to $4.4 \mathrm{~V}$ and $4.8 \mathrm{~V}$, respectively. Both samples were obtained by opening each charged state $(4.4 \mathrm{~V}$ and $4.8 \mathrm{~V})$ coin cell and then removing some materials from the electrode. Samples of both charge states were washed several times with dimethyl carbonate to remove any residual electrolyte on particle surfaces.

In operando BCDI. In operando BCDI measurements of $\mathrm{Li}_{2} \mathrm{MnO}_{3}$ material in a coin cell with $3 \mathrm{~mm}$ diameters Kapton windows were performed at beamline 34-ID-C, APS, ANL. Coherent diffraction patterns around [003] Bragg peak were collected using rocking curve scans. To minimize any negative impact on the battery due to X-rays, scans were taken every hour. Phase retrieval scripts used were written by J. Clark in previously reported work. ${ }^{4}$

In operando X-ray absorption spectroscopy. In operando X-ray absorption spectra were collected at beamline 12-BM-B, APS, ANL, using a perforated CR2032-type coin cell also used in operando PXRD. Electrodes were made of the same as materials as those used in electrochemical tests. Experiments were conducted in transmission mode using a Si (111) double-crystal monochromator across $\mathrm{Ni}(8333 \mathrm{eV})$ and $\mathrm{Mn}(6539 \mathrm{eV}) \mathrm{K}$-edge for LR-NCM and $\mathrm{Mn} \mathrm{K}$-edge for Li-rich phase $\mathrm{Li}_{2} \mathrm{MnO}_{3}$. A reference X-ray absorption spectrum of metallic $\mathrm{Ni}$ and/or Mn K-edge spectrum was simultaneously collected using Ni and Mn foil. X-ray absorption data was analyzed using IFEFFIT-Athena and Artemis. During analysis of the MO bond length, a coordination number of 6 was applied for the first coordination shell without consideration for Jahn-Teller effects.

In operando 2D TXM-XANES experiments. In operando 2D TXM-XANES experiments were performed at beamline 8-BM-B of the APS, a transition beamline from NSLS-II. 
Electrodes were made of $40 \mathrm{wt} \%$ active materials, $40 \mathrm{wt} \%$ carbon black, and $20 \mathrm{wt} \%$ binder (PVDF). It should be noted that hard X-rays can transmit through carbon, enclosed carbon black and carbon papers, and binder. Therefore, these inactive materials, which are necessary for battery manufacturing, are not be observed during characterization. Coin cell's were fixed in a battery holder and mounted on a motorized stage with $X, Y, Z$, and $\theta$ dimensions and aligned for X-ray transmittance. Cells were continuously cycled at a rate of $c a$. 1/10 C during the absorption-contrast and background images were collected under dynamic conditions. A $2 \mathrm{k} \times$ $2 \mathrm{k}$ CCD camera with a field view of $40 \times 40 \mu \mathrm{m}^{2}$ was used. To record material phase transformations, a full series of XANES images were collected at every charge states. Complete XANES images were collected by scanning K-edge (e.g. Ni, 8,333 eV) from 8,313 to $8,413 \mathrm{eV}$ at each $2 \mathrm{eV}$, which generated $512 \times 512$ XANES spectra with $4 \times 4$ binned pixels, corresponding to $\sim 80 \mathrm{~nm}$ output pixel size. The exposure time for each XANES image was 15 S.

A custom program (Matlab, R2011b) developed in-house was used to analyze all the TXMXANES data. ${ }^{5}$ First, background TXM images collected at every energy were applied to all the corresponding sample XANES images. Then, we extracted the full XANES spectrum (xray intensity v.s. energy) for each pixel. Based on Beer's Law, the attenuation coefficient $\mu$ for the given phase and thickness $t$ could be defined as:

$\frac{\mathrm{I}}{\mathrm{I}_{0}}=\exp (-\mu(\mathrm{E}) \mathrm{t})=\exp \left(-\mu_{L R}-N_{C M} \mathrm{t}_{\mathrm{LR}-\mathrm{NCM}}\right) \cdot \exp \left(-\mu_{\mathrm{CLR}-\mathrm{NCM}} \mathrm{t}_{\mathrm{CLR}-\mathrm{NCM}}\right)$

where $I_{0}$ is the incident X-ray intensity and $I$ is corresponding X-ray intensity after the attenuating phase. Note that $\mu$ is a function of energy and can be attributed to two phases: LRNCM and CLR-NCM (the fully charged phase).

The scaled $-\ln \left(I / I_{0}\right)$ at each of the 512 x 512 pixels was then fitted with the linear combination of two $\mu$ values. Weighting factor ratios were analogous to the thickness fraction and therefore represented their volume fraction.

$$
-\ln \left(\frac{\mathrm{I}}{\mathrm{I}_{0}}\right)=\mu_{\mathrm{LR}-\mathrm{NCM}} \mathrm{t}_{\mathrm{LR}-\mathrm{NCM}}+\mu_{\mathrm{CLR}-\mathrm{NCM}} \mathrm{CLLR}_{-\mathrm{NCM}}
$$

Spectrum fitting was carried out by minimizing measurement error ( $R$ value) for each spectrum at each pixel, which is defined as:

$\mathrm{R}=\sum_{\mathrm{Ei}}^{\mathrm{Ef}}(\text { dataE }-\mathrm{refE})^{2} / \sum_{\mathrm{Ei}}^{\mathrm{Ef}} \mathrm{dataE}^{2}$

where $E i$ is $8,313 \mathrm{eV}$ and $E f$ is $8,413 \mathrm{eV}$ for $\mathrm{Ni} \mathrm{K}$-edge mappings. dataE is the normalized spectrum for the given energy $\mathrm{E}$ at each pixel, and refE is the possible fitting reference value that is a linear combination of X-ray attenuation of the pristine LR-NCM and the fully 
charged phase CLR-NCM. For the ex-situ 2D chemical mappings of LR-NCM particles at Mn K-edge, the same fitting method was used. The only changes made were to Ei and Ef in equation 2, which became $6519 \mathrm{eV}$ and $6619 \mathrm{eV}$, respectively. 
Table S1. Lattice parameters for the two phases present in pristine Li-rich material.

\begin{tabular}{cccc}
\hline & & & Pristine LR-NCM \\
\hline Phase 1: & Phase fraction & & $\mathbf{0 . 5 6 ( 3 )}$ \\
Rhombohedral LiTMO & & $2.84900(1)$ \\
Space group: $R \overline{3} m$ & Lattice parameters $(\AA)$ & $\mathrm{a}=\mathrm{b}$ & $14.2218(1)$ \\
& Unit cell volume $\left(\AA^{3}\right)$ & $\mathrm{c}$ & $99.970(1)$ \\
\hline & Phase fraction & $\mathrm{V}$ & $\mathbf{0 . 4 4 ( 3 )}$ \\
Phase 2: & & $\mathrm{a}$ & $4.9506(4)$ \\
Monoclinic $\mathrm{Li}_{2} \mathrm{MnO}_{3}$-like & Lattice parameters $(\AA)$ & $\mathrm{b}$ & $8.5212(6)$ \\
structure & & $\mathrm{c}$ & $5.0258(2)$ \\
Space group: $C 2 / m$ & Unit cell volume $\left(\AA^{3}\right)$ & $\beta$ & $109.36(4)$ \\
& $\mathrm{Rwp}(\%)$ & $\mathrm{V}$ & $200.02(2)$ \\
\hline \multirow{2}{*}{ Agreement factors } & Rp $(\%)$ & \multicolumn{2}{c}{} \\
\hline
\end{tabular}


Table S2. Atom coordinates and displacement parameters from structure refinement results.

\begin{tabular}{|c|c|c|c|c|c|c|c|}
\hline & $\begin{array}{l}\text { Wyckoff } \\
\text { position }\end{array}$ & Element & $\mathrm{x}$ & $\mathrm{y}$ & Z & B & Occ. \\
\hline \multirow{7}{*}{$\begin{array}{c}\text { Phase } 1 \\
R \overline{3} m\end{array}$} & \multirow{3}{*}{$3 a$} & $\overline{\mathrm{Li}}$ & \multirow{4}{*}{0} & \multirow{4}{*}{0} & \multirow{4}{*}{0} & $1.10(2)$ & $0.20(3)$ \\
\hline & & Co & & & & $0.19(1)$ & $0.13(3)$ \\
\hline & & $\mathrm{Ni}$ & & & & $0.19(1)$ & $0.11(3)$ \\
\hline & \multirow{3}{*}{$3 b$} & $\mathrm{Mn}$ & & & & $0.19(1)$ & $0.58(4)$ \\
\hline & & $\mathrm{Li}$ & \multirow{2}{*}{0} & \multirow{2}{*}{0} & \multirow{2}{*}{$1 / 2$} & $0.5(1)$ & $0.98(3)$ \\
\hline & & $\mathrm{Ni}$ & & & & $0.5(1)$ & $0.02(3)$ \\
\hline & $6 c$ & $\mathrm{O}$ & 0 & 0 & $0.2619(4)$ & $0.18(2)$ & 1.00 \\
\hline \multirow{9}{*}{$\begin{array}{c}\text { Phase } 2 \\
C 2 / m\end{array}$} & $2 \mathrm{c}$ & $\mathrm{Li}$ & 0 & 0 & $1 / 2$ & $0.4(3)$ & $0.98(2)$ \\
\hline & $4 \mathrm{~h}$ & $\mathrm{Li}$ & 0 & $0.689(2)$ & $1 / 2$ & $0.4(3)$ & $0.98(2)$ \\
\hline & \multirow{2}{*}{$2 b$} & $\mathrm{Li}$ & \multirow{2}{*}{0} & \multirow{2}{*}{$1 / 2$} & \multirow{2}{*}{0} & $0.37(2)$ & 0.60 \\
\hline & & $\mathrm{Mn}$ & & & & $0.37(2)$ & 0.40 \\
\hline & \multirow{3}{*}{$4 \mathrm{~g}$} & Mn & \multirow{3}{*}{0} & \multirow{3}{*}{$0.174(2)$} & \multirow{3}{*}{0} & $0.52(1)$ & $0.76(5)$ \\
\hline & & $\mathrm{Ni}$ & & & & $0.52(1)$ & $0.17(5)$ \\
\hline & & Co & & & & $0.52(1)$ & $0.17(5)$ \\
\hline & $4 \mathrm{i}$ & $\mathrm{O}$ & $0.226(3)$ & 0 & $0.218(3)$ & $0.32(1)$ & 1.00 \\
\hline & $8 \mathrm{j}$ & $\mathrm{O}$ & $0.252(6)$ & $0.329(4)$ & $0.231(5)$ & $0.32(1)$ & 1.00 \\
\hline
\end{tabular}



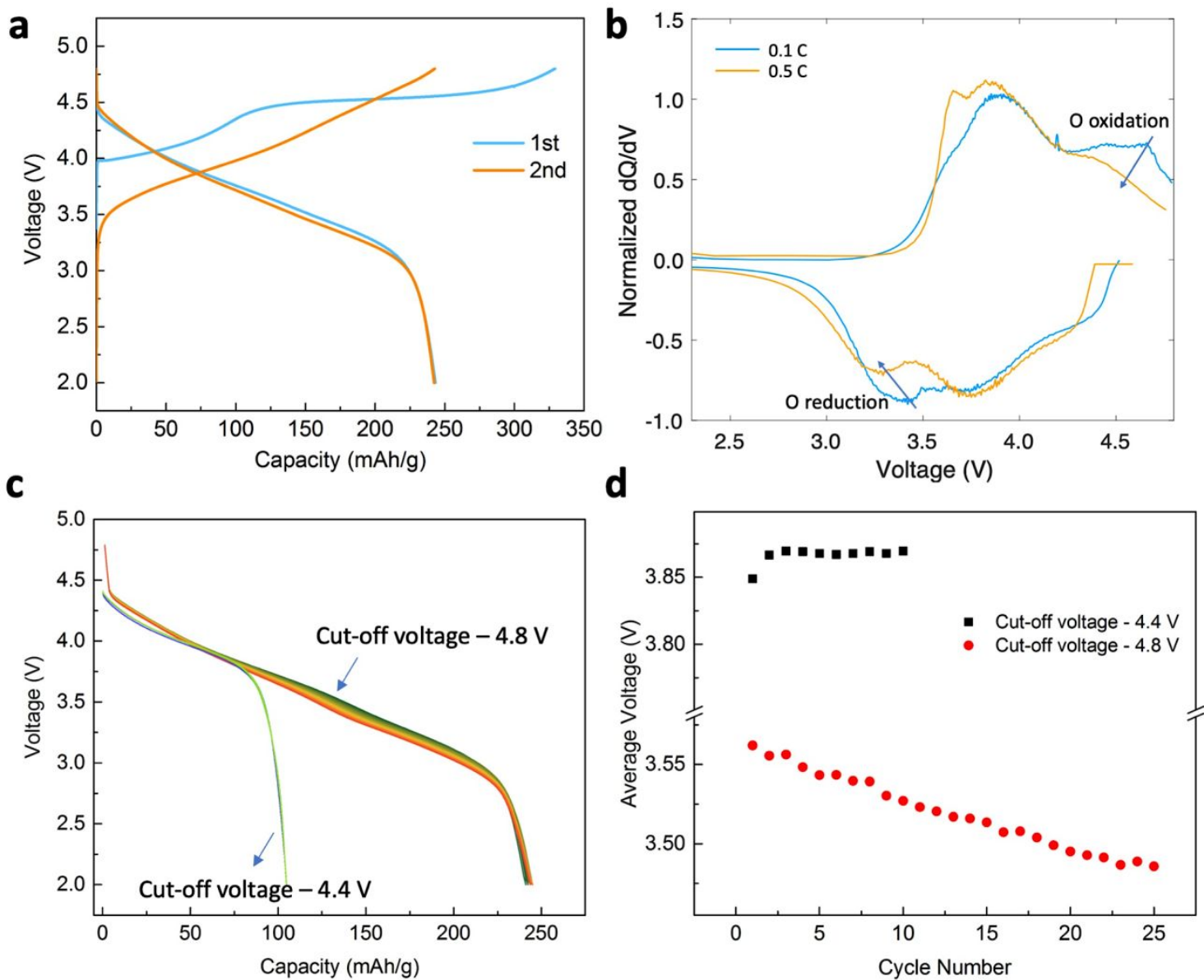

Figure S1. Electrochemical performance of LR-NCM cathode. (a) The first two chargedischarge cycles under the voltage range of 2.0-4.8 V. (b) Normalized $d Q / d V$ curves at different current density. (c) The discharge profiles and (d) average discharge voltages at different cycles under various cut-off voltages. 


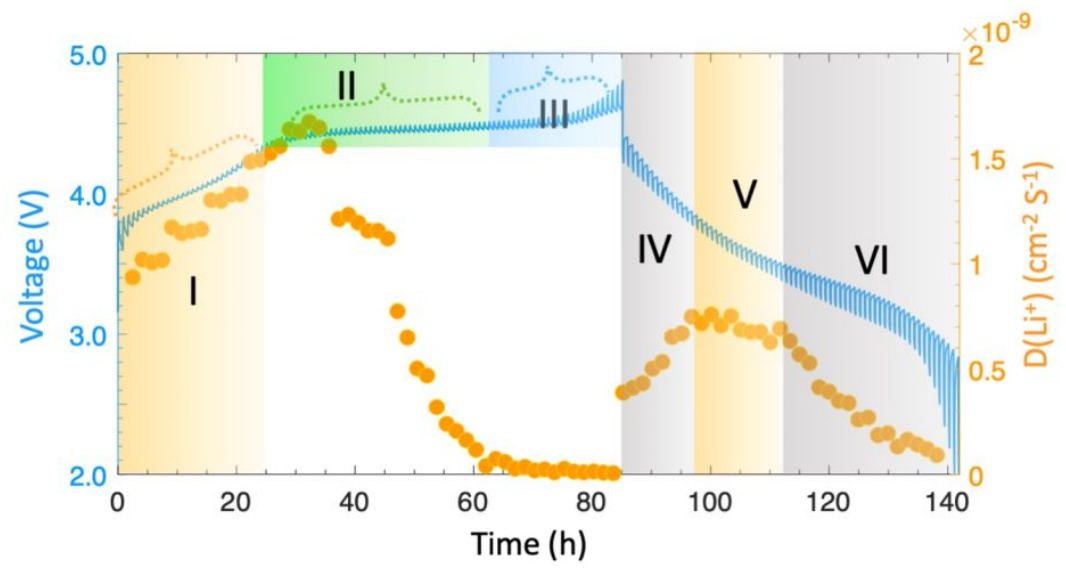

Figure S2. Reaction kinetics of LR-NCM during the initial cycle analyzed by GITT measurements. The $\mathrm{Li}^{+}$diffusion coefficient is calculated for each current pulse. 


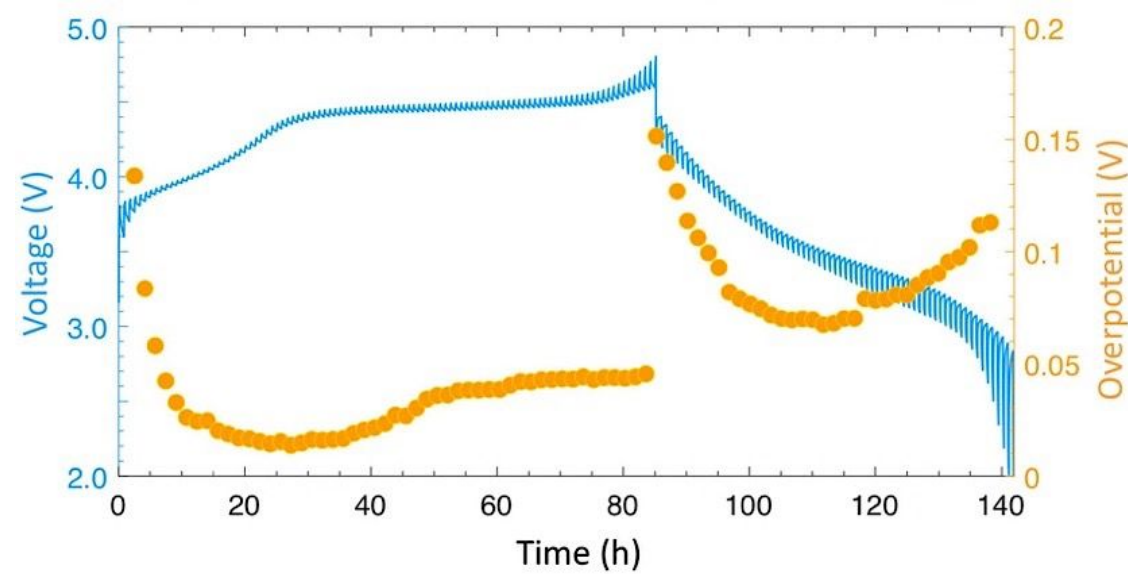

Figure S3. GITT curves and corresponding over-potentials at each current pulse.

Overpotential is defined by the voltage difference between the end of each interrupted current pulse and the end of relaxation. 

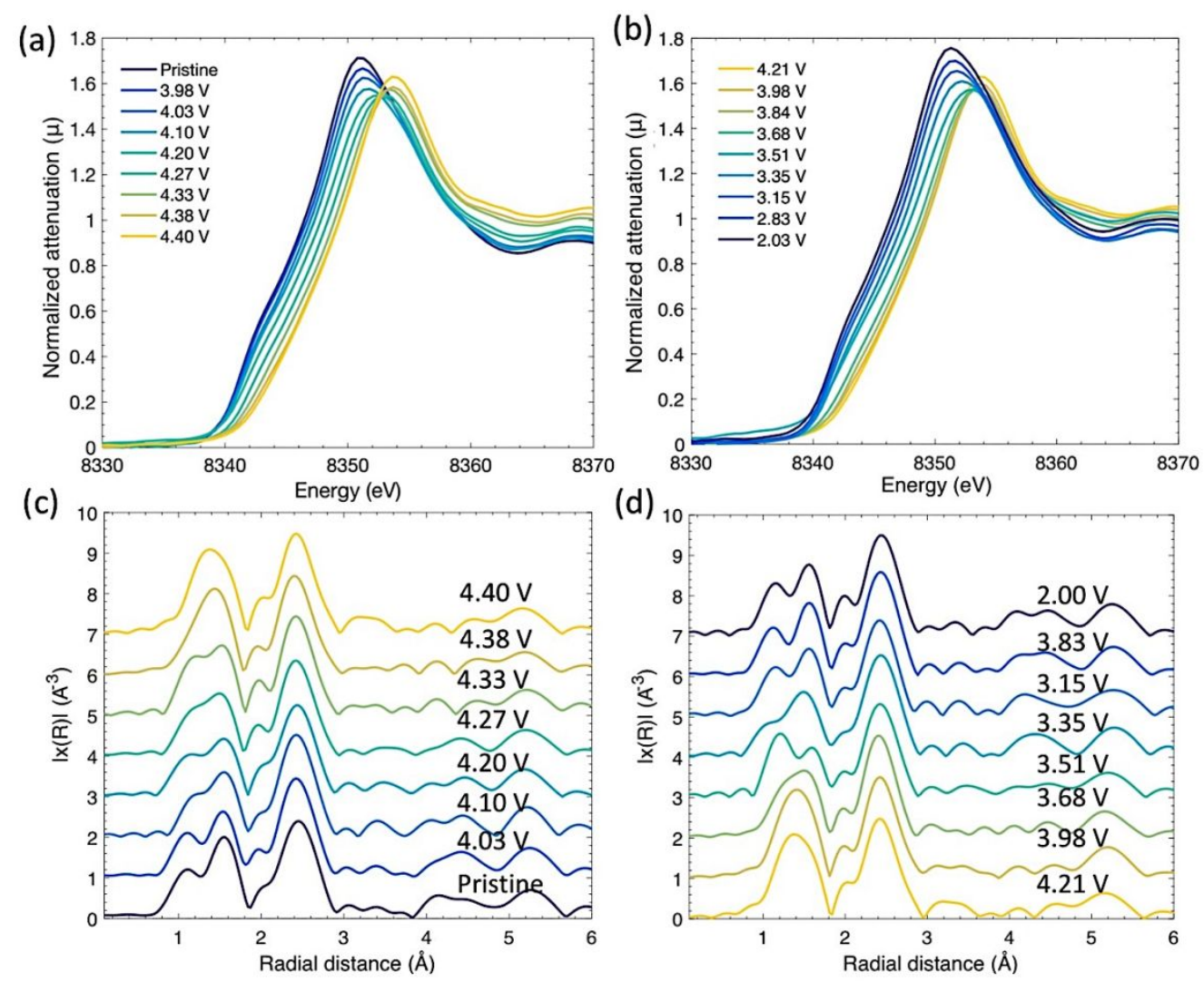

Figure S4. In situ XANES and EXASF at Ni K-edge at the cut-off voltage of 4.4 V. In situ XANES spectrums of LR-NCM electrode during (a) the first charge and (b) discharge processes at the cut-off voltage of $4.4 \mathrm{~V}$, and the corresponding EXASF curves (c) and (d), respectively. 
(a)

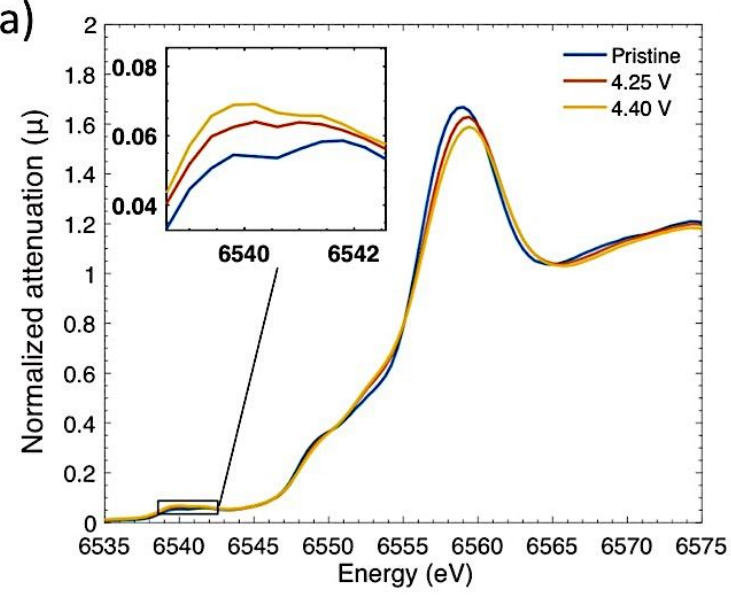

(c)

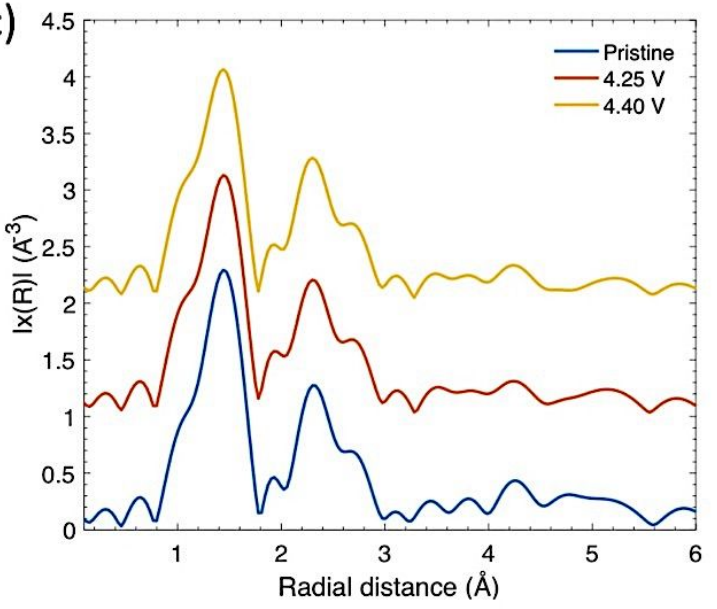

(b)

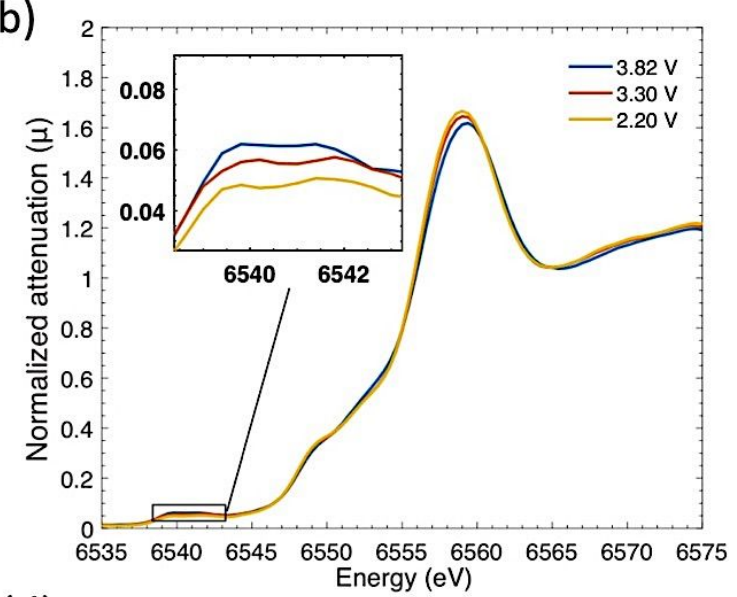

(d)

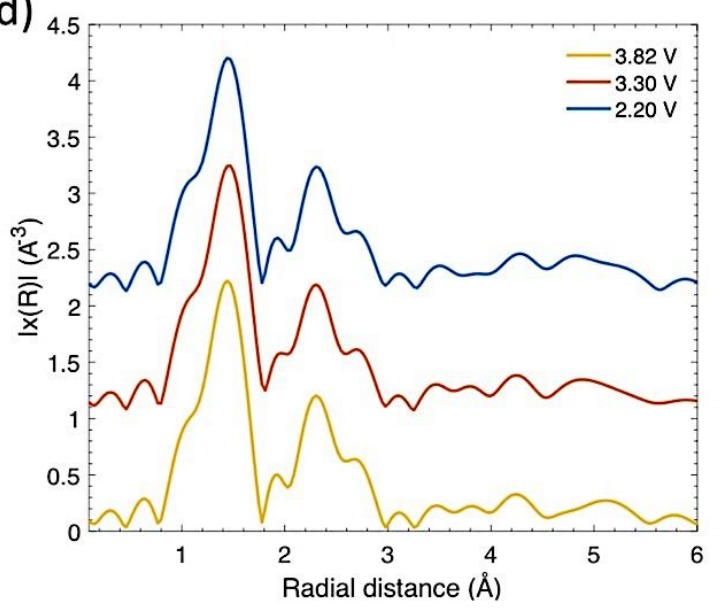

Figure S5. In situ XANES and EXAFS at Mn K-edge at the cut-off voltage of $4.4 \mathrm{~V}$. The in situ XANES spectrums of LR-NCM electrode during the (a) first charge and (b) discharge processes at the cut-off voltage of $4.4 \mathrm{~V}$, and the corresponding EXAFS curves (c) and (d), respectively. 


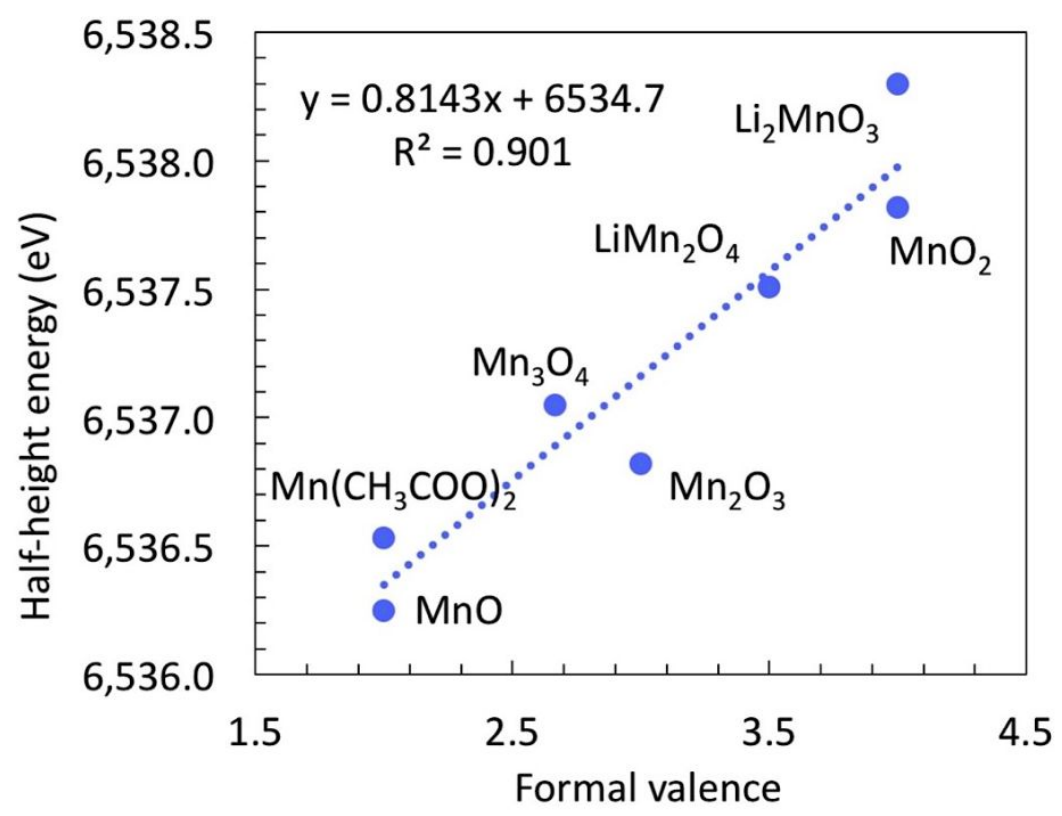

Figure S6. Linear fit of the lower, pre-edge, half-height energy for the various sample standard valences. 


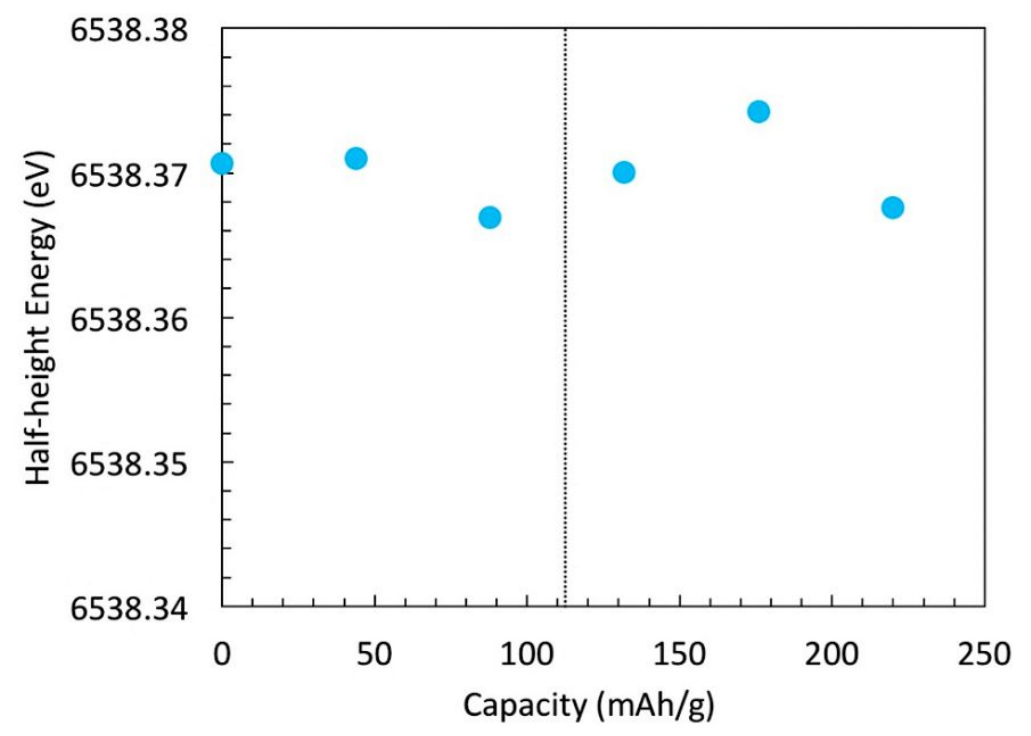

Figure S7. Half-height energy of lower pre-edge changes at Mn K-edge during the first cycle at a $4.4 \mathrm{~V}$ cut-off. 
a

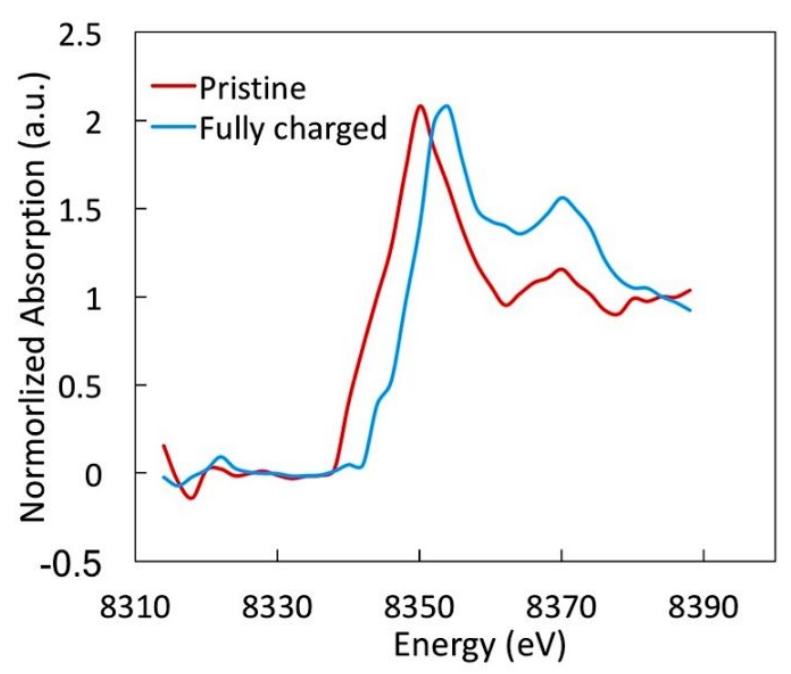

b

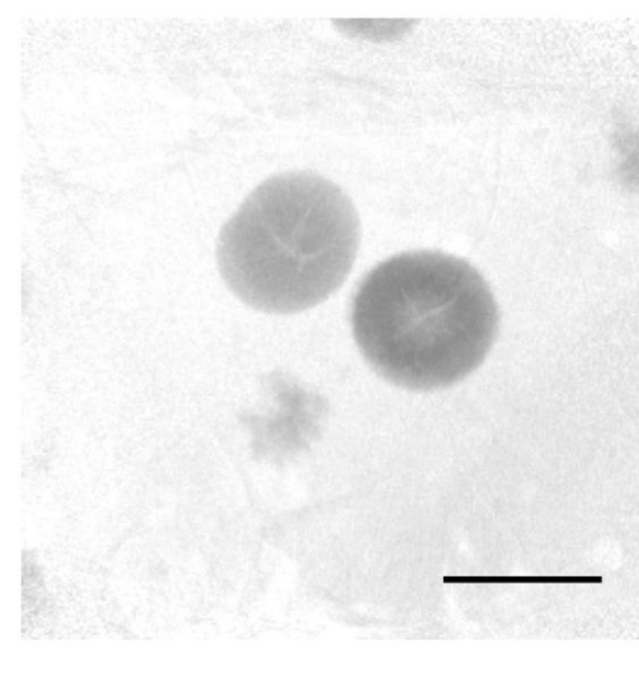

Figure S8. In operando TXM experimental data. (a) Two reference XANES spectra for the in operando TXM experiments fitting. (b) The selected field of view on the LR-NCM electrode. 

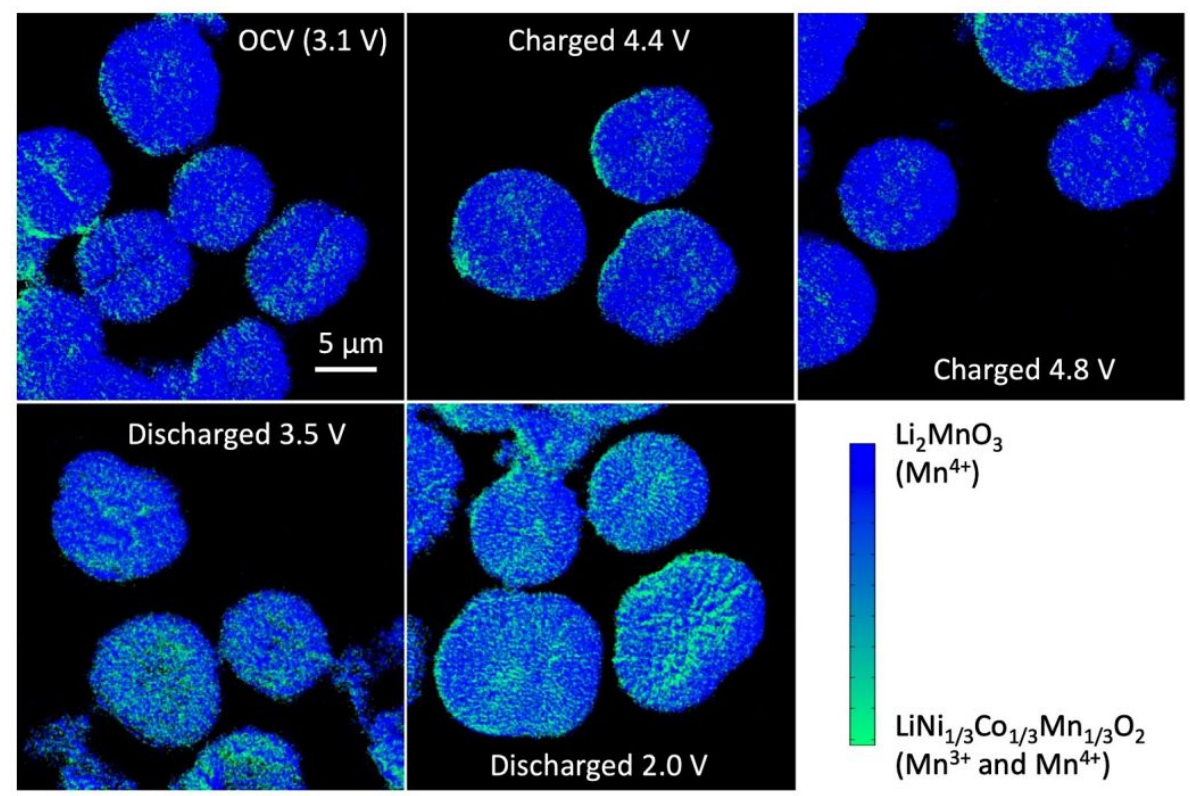

Figure S9. Ex-situ 2D chemical phase mapping at Mn K-edge on the LR-NCM electrode during the first cycle. 2D chemical phase mappings were performed on the LR-NCM particles at various states during the initial cycle. The blue and green in the mappings correspond to $\mathrm{Mn}^{4+}$ in the Li-rich phase and the $\mathrm{Mn}$ valence in the $\mathrm{LiNi}_{1 / 3} \mathrm{Co}_{1 / 3} \mathrm{Mn}_{1 / 3} \mathrm{O}_{2}$ material, respectively. 


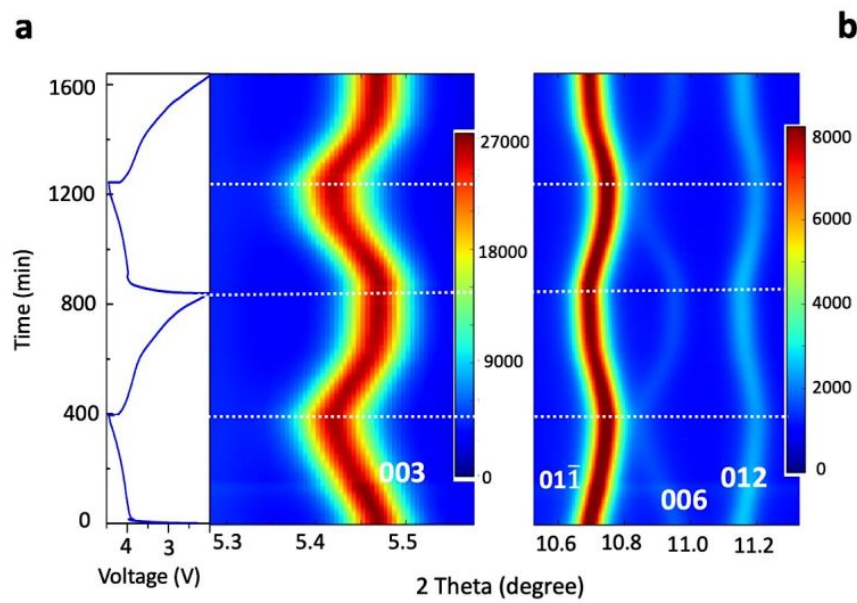

b Lattice Parameters $c(\AA)$

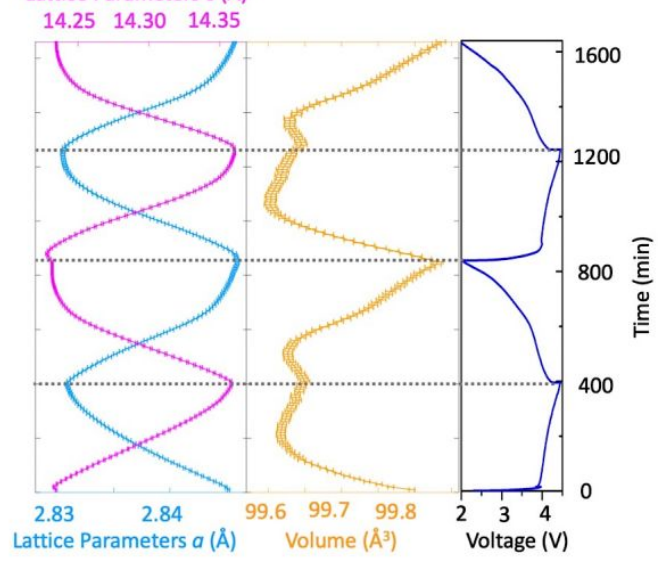

Figure S10. Structural evolution of LR-NCM. (a) Contour plots of in operando PXRD data and the corresponding charge-discharge curves at a $4.4 \mathrm{~V}$ cut-off. (b) Cell parameters with error bars $(a, c$, and $V)$ obtained by fitting each XRD patterns with rhombohedral $R \overline{3} m$ space groups during the first two cycles. 


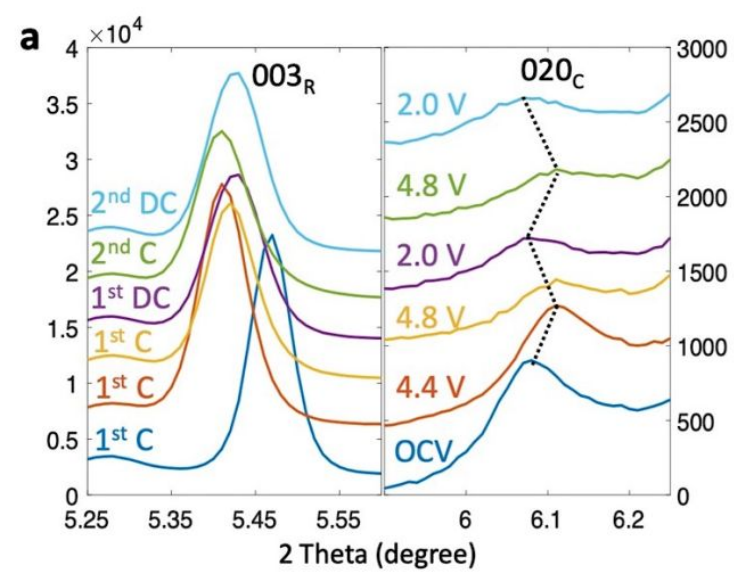

b

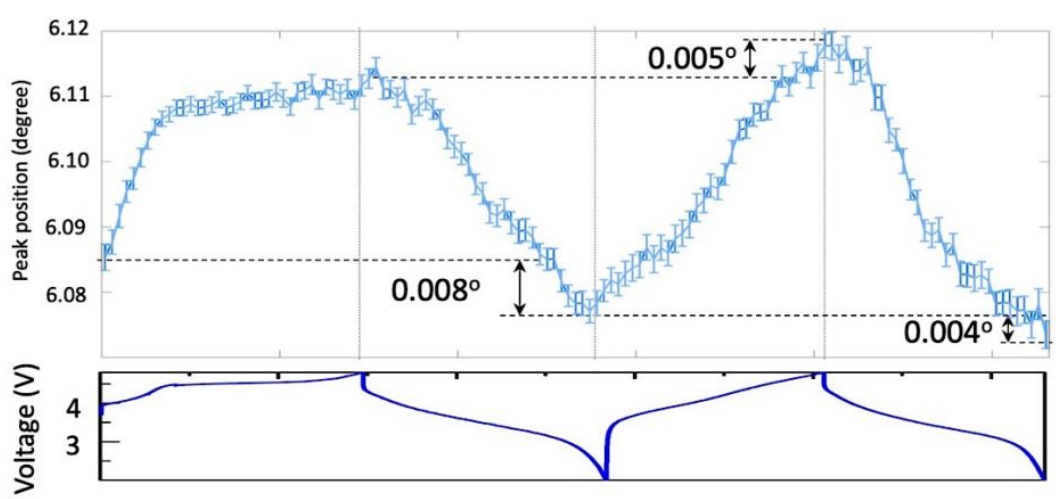

Figure S11. (a) Selected rhombohedral-layered $R-3 \mathrm{~m} 003$ peaks (denoted as $003_{\mathrm{R}}$ ) and the monoclinic $C 2 / \mathrm{m} 020$ peaks (denoted as $020_{\mathrm{C}}$ ) of in operando HRXRD patterns at different charge states. $1^{\text {st }} \mathrm{C}, 1^{\text {st }} \mathrm{DC}, 2^{\text {nd }} \mathrm{C}$ and $2^{\text {nd }} \mathrm{DC}$ stand for the states at the $1^{\text {st }}$ charge, $1^{\text {st }}$ discharge, $2^{\text {nd }}$ charge and $2^{\text {nd }}$ discharge, respectively. Corresponding voltages are also labeled on the right figure. (b) The 020 peak position of the monoclinic C2/m phase in LR-NCM changes during the first two cycles. 


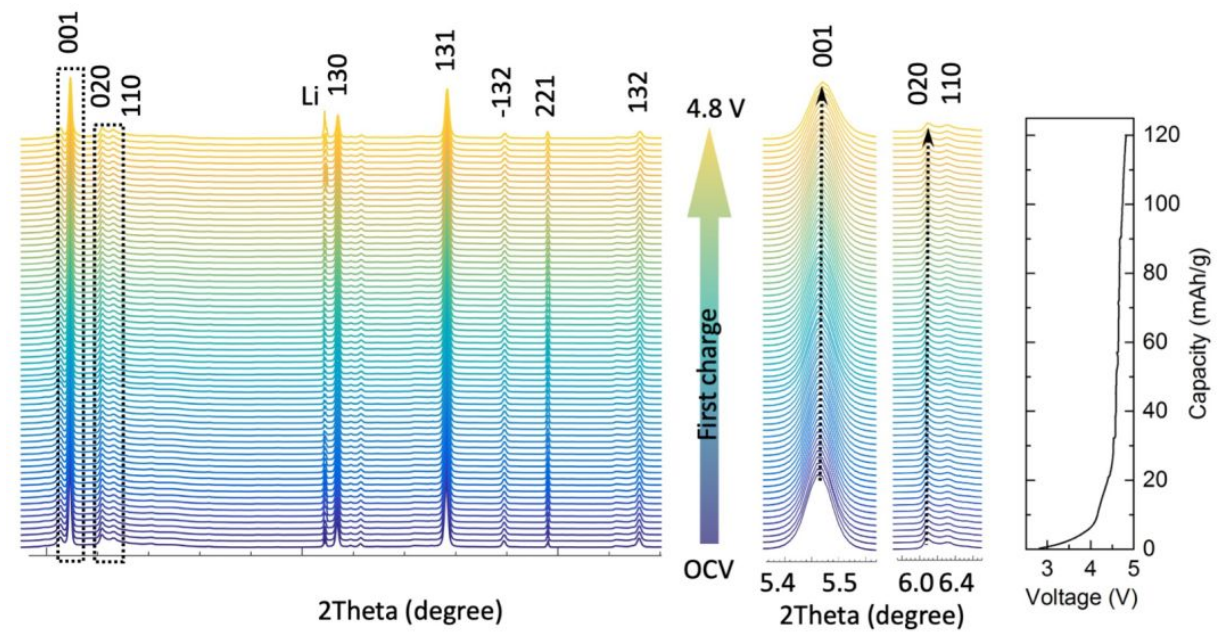

Figure S12. Structural changes of the pure $\mathrm{Li}_{2} \mathrm{MnO}_{3}$. In operando PXRD curves of $\mathrm{Li}_{2} \mathrm{MnO}_{3}$ during the first charge process. 


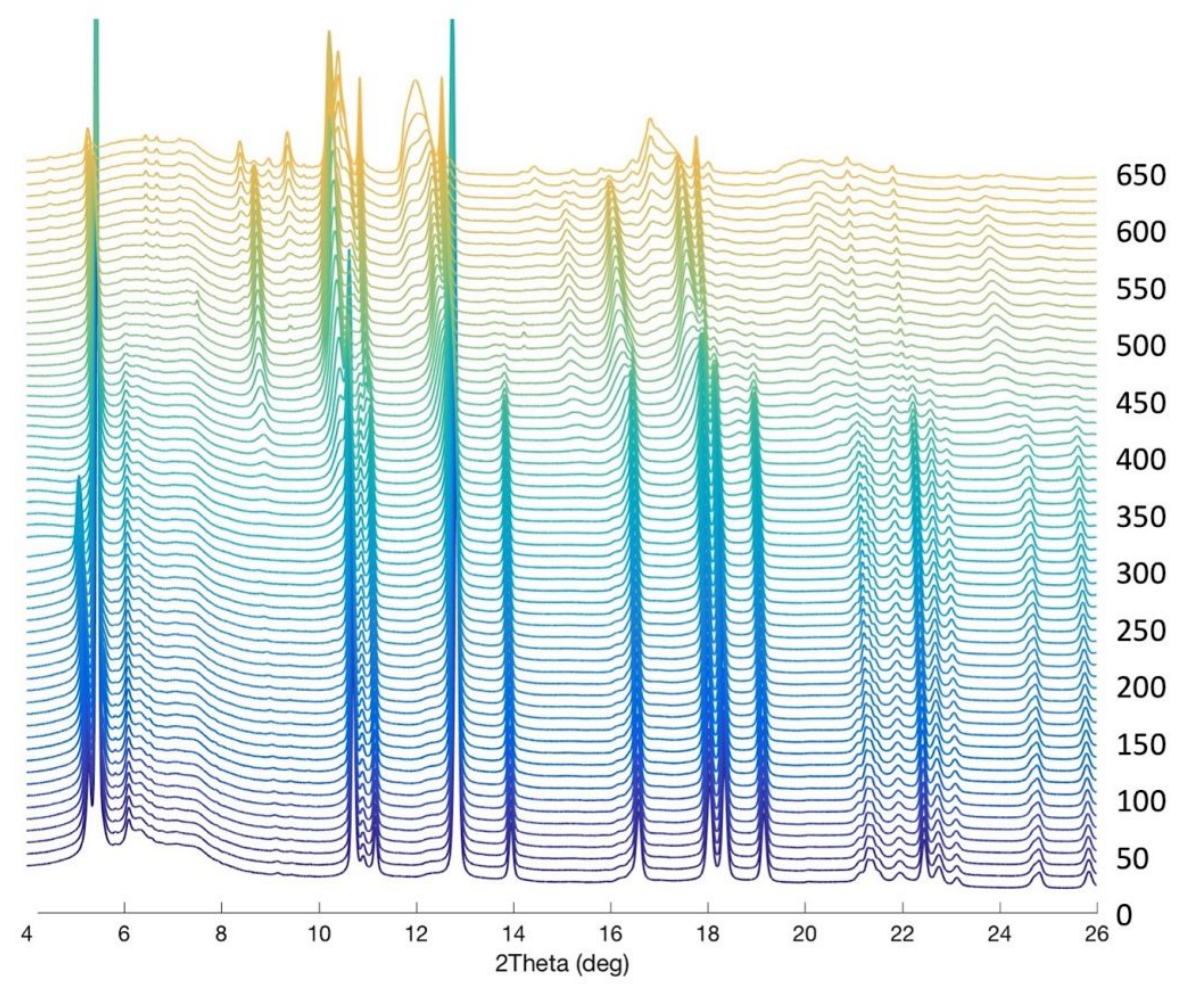

Figure S13. Thermal stability of the LR-NCM material after charge to $4.4 \mathrm{~V}$. In operando TR-XRD of the LR-NCM electrode after charge $4.4 \mathrm{~V}$ and heating from $30^{\circ} \mathrm{C}$ to $650^{\circ} \mathrm{C}$. 


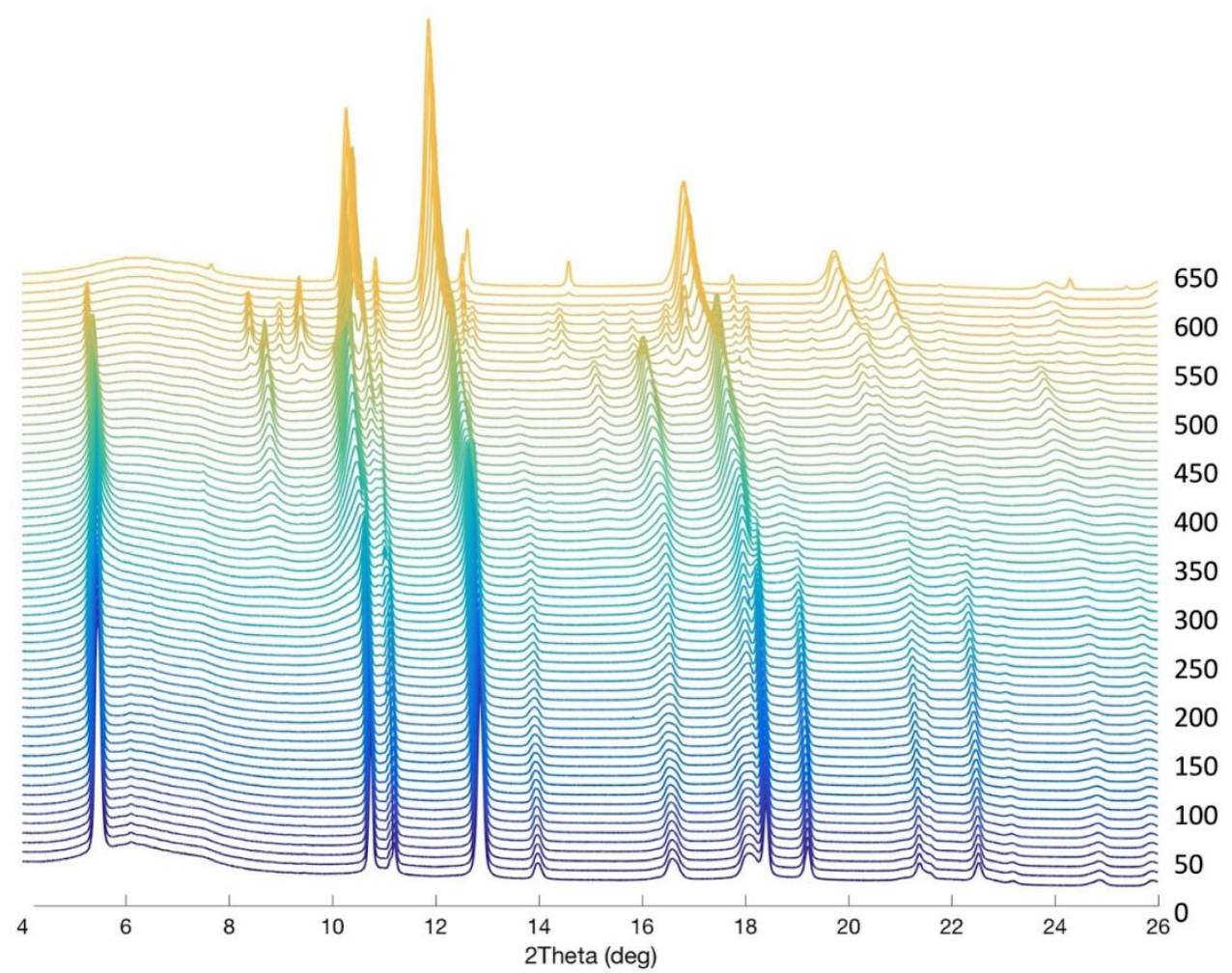

Figure S14. Thermal stability of the LR-NCM material after charge to $4.8 \mathrm{~V}$. In operando TR$\mathrm{XRD}$ of the LR-NCM electrode after charge to $4.8 \mathrm{~V}$ and heating from $30^{\circ} \mathrm{C}$ to $650^{\circ} \mathrm{C}$.

Reference

1. Chen, C.; Geng, T.; Du, C.; Zuo, P.; Cheng, X.; Ma, Y.; Yin, G., Oxygen vacancies in $\mathrm{SnO}_{2}$ surface coating to enhance the activation of layered Li-Rich $\mathrm{Li}_{1.2} \mathrm{Mn}_{0.54} \mathrm{Ni}_{0.13} \mathrm{Co}_{0.13} \mathrm{O}_{2}$ cathode material for Li-ion batteries. J. Power Sources 2016, 331, 91-99.

2. Wang, L.; Wang, J.; Guo, F.; Ma, L.; Ren, Y.; Wu, T.; Zuo, P.; Yin, G.; Wang, J., Understanding the initial irreversibility of metal sulfides for sodium-ion batteries via operando techniques. Nano Energy 2018, 43, 184-191.

3. Nam, K.-W.; Bak, S.-M.; Hu, E.; Yu, X.; Zhou, Y.; Wang, X.; Wu, L.; Zhu, Y.; Chung, K.-Y.; Yang, X.-Q., Combining in situ synchrotron X-ray diffraction and absorption techniques with transmission electron microscopy to study the origin of thermal instability in overcharged cathode materials for lithium-ion batteries. Adv. Funct. Mater. 2013, 23 (8), 1047-1063.

4. Clark, J. N.; Huang, X.; Harder, R.; Robinson, I. K., High-resolution three-dimensional partially coherent diffraction imaging. Nat. Commun. 2012, 3, 993-999.

5. Wang, L.; Wang, J.; Zhang, X.; Ren, Y.; Zuo, P.; Yin, G.; Wang, J., Unravelling the origin of irreversible capacity loss in $\mathrm{NaNiO}_{2}$ for high voltage sodium ion batteries. Nano Energy 2017, 34, 215-223. 